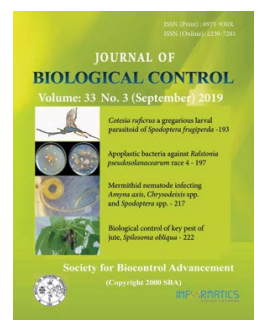

Research Note

\title{
Influence of weaver ant, Oecophylla smaragdina Fabricius (Hymenoptera: Formicidae) on mealybug parasitism by encyrtids (Chalcidoidea: Encyrtidae)
}

\author{
T. NALINI* and S. MANICKAVASAGAM \\ Department of Entomology, Faculty of Agriculture, Annamalai University, Chidambaram - 608002, Tamil Nadu, India \\ ${ }^{*}$ Corresponding author E-mail: nalini_jk@yahoo.com
}

\begin{abstract}
The influence of Oecophylla smaragdina Fabricius on parasitism of Phenacoccus solenopsis Tinsley and Ferrisia virgata Cockerell by Aenasius arizonensis (Girault) (= Aenasius bambawalei Hayat) and A. advena Compere were studied under laboratory conditions. The number of surviving A. arizonensis and A. advena was 3.40 and 5.20 at $20^{\text {th }}$ minute, and 1.0 and 0.8 at $60^{\text {th }}$ minute, respectively. Per cent parasitism was 13.60 and 10.00 in treatment with $O$. smaragdina for $A$. arizonensis and $A$. advena, respectively. Per cent mortality due to $O$. smaragdina attack was 93.33 and 94.67 for $A$. arizonensis and $A$. advena, respectively.
\end{abstract}

KEY WORDS: Aenasius arizonensis, Aenasius advena, Oecophylla smaragdina, parasitism

(Article chronicle: Received: 09-05-2018; Revised: 12-02-2019; Accepted: 02-03-2019)

Mealybugs once considered as minor pests have assumed the major pest status due to their polyphagous nature coupled with high reproductive capacity with short life cycle which is more favoured due to prolonged drought and quick dispersal through wind, seeds and planting materials. During 2004-05, there was a severe incidence of Phenacoccus solenopsis Tinsely on cotton in Haryana and subsequently in Punjab, Gujarat, Maharashtra and Karnataka. In Tamil Nadu the incidence was quite severe only during 2006-07 season attacking cotton, sunflower, many vegetable crops and weed hosts resulting in heavy yield loss (Suresh et al., 2010). Phenacoccus solenopsis was found to be the predominant mealybug species, comprising $95 \%$ of the samples examined. This mealybug now appears to be widespread on cotton in almost all cotton-growing states of the country (Dhawan et al., 2008). Earlier, two tailed mealybug, Ferrisia virgata (Cockerell) and pink mealybug, Maconellicoccus hirsutus (Green) were considered as major polyphagous coccid pests in India. In addition, citrus mealybug, Planococcus citri, (Risso) and long tailed mealybug, Pseudococcus longispinus (Tag-Tazz.) were also recorded on few fruit crops and on coconut (Suresh and Kavitha, 2007). Therefore, as alien invasive pest species in India, $P$. solenopsis and $F$. virgata are obvious target for classical biological control.
The importance of the Encyrtidae in mealybug management is not surprising since almost all the members of the family are primary parasitoids of mealybugs; with the vast majority of these species belonging to the subfamily Tetracneminae (Noyes, 2000). Aenasius arizonensis and A. advena are recovered most frequently from $P$. solenopsis and F. virgata (Nalini and Manickavasagam, 2011). Several studies have shown that ants tend on honeydew-producing hemipteran insects such as mealybugs to access a renewable and defensible source of carbohydrates energy-rich food (Carroll et al., 1973). In return, the ants render protection against parasitoids, predators and even their competitors (Hölldobler and Wilson, 1990; Jiggins et al., 1993), as well as sanitation (Buckley, 1987). The relative effectiveness of the weaver ant Oecophylla smaragdina, a dominant canopy ant in India in reducing the incidence of predation and parasitization in different hemipteran has rarely been examined. By providing protection to the mealybugs from natural enemies, the presence of certain ant species can be detrimental to the impact of biological control (Tanga, 2012; Wimp and Whitham, 2001; MartinezFerrer, 2003). So, with this background, the present study was focused on the influence of $O$. smaragdina on encyrtids.

\section{Culturing of Phenacoccus solenopsis and Ferrisia virgata}

The cultures of $P$. solenopsis and F. virgata were 
established in the laboratory from individuals collected from the fields. Both mealybug species cultures were maintained separately in two incubators at $32 \pm 2^{\circ} \mathrm{C}, 65 \pm 5$ per cent $\mathrm{RH}$ and L10:D14 on potato sprouts kept in plastic tubs $(10 \mathrm{~cm}$ high and $33 \mathrm{~cm}$ dia.), with fine sand of $5 \mathrm{~cm}$ depth. Six to twelve potato sprouts were placed (depending upon size of potatoes) per tub and moistened regularly. Two adult females of $P$. solenopsis and F. virgata were released per potato separately. After one to two weeks (P. solenopsis) and two to three weeks (F. virgata) of inoculation, the potato sprouts developed into second and third instar stages. This inoculation was repeated on fresh potato sprouts every three weeks to get a continuous supply of mealybugs.

\section{Culturing of Aenasius arizonensis and A. advena}

The cultures of $A$. arizonensis Hayat and A. advena Compere were established in the laboratory from the mummies of the respective mealybugs collected from the fields. The parasitoids emerged were identified and cultured on $P$. solenopsis and F. virgata, respectively. Adult parasitoids (five pairs) were released in to a glass container $(15 \mathrm{~cm}$ long and $10 \mathrm{~cm}$ dia) covered with khadda cloth containing 1-2 potato sprouts supporting second and third instars of $P$. solenopsis and F. virgata and removed after $48 \mathrm{~h}$ of oviposition. A streak of 100 per cent honey was placed on the inside wall of glass container. Ten to fifteen days after parasitization adults started emerging out from the mealybug mummies. Both parasitoid cultures were kept separately in two incubators and maintained at $32 \pm 2^{\circ} \mathrm{C}, 65 \pm 5$ per cent RH and L10: D14.

\section{Experimental procedure}

Fifty third instar P. solenopsis were placed on a potato sprouts in an open Petri plate $(10 \mathrm{~cm}$ dia) from the culture maintained in the laboratory. Weaver ant, Oecophylla smaragdina nest was collected from the orchard of Faculty of Agriculture, Annamalai University and placed inside a plastic container $(22.5 \mathrm{~cm}$ long and $11 \mathrm{~cm} \mathrm{dia)} \mathrm{secured} \mathrm{with} \mathrm{a}$ lid and transferred to the laboratory. A set up was arranged to mimic the natural condition as far as possible. A transparent cage $(30 \mathrm{~cm} \times 31 \mathrm{~cm} \times 51.5 \mathrm{~cm})$ with one round vent on one of its sides and with a top lid was used to conduct the experiment. Through the top lid the parasitoids were introduced, secured with khadda cloth to prevent escape of parasitoids, after keeping the Petri plate containing potato sprouts with mealybugs. The round vent on one of its sides was fitted with the container having the weaver ant nest. Ants were allowed to forage freely for the honey dew for $48 \mathrm{~h}$ prior to the experiment. A streak of 100 per cent honey was placed on the side wall of the cage. Fifteen mated females of A. arizonensis were introduced with a single tube aspirator through the top lid by gently blowing through the tube. Observations were made 10 min after the release of parasitoids. The number of ants and parasitoids inside the cage was recorded during one min period at every $10 \mathrm{~min}$ interval for $1 \mathrm{~h}$. Parasitoids were left in the cage for $24 \mathrm{~h}$ after which they were removed and the number of surviving, dead and/or missing if any, were recorded.

Hand lens (15X) was used to search the missing parasitoids in the ant nest as well as on mealybug colony. After $24 \mathrm{~h}$, mealybugs on the potato sprouts in the cage were transferred to a glass container covered with khadda cloth containing two potato sprouts. After mummification, hosts were transferred individually into $5 \mathrm{ml}$ glass vials and observed daily for the emergence of parasitoid offsprings from 10th day after oviposition. Control (ant-free treatment) was also maintained. With this single set up, the test was repeated five times at five different dates and considered as replications. Per cent parasitism and per cent mortality were calculated.

$\begin{aligned} & \text { Percent mortality of } \\ & \text { the parasitoids }\end{aligned}=\frac{\text { The number of dead }+ \text { missing parasitoids }}{\text { Total number of parasitoids }} \times 100$

(Mgocheki and Addison, 2009)

Per cent parasitism was calculated. The same protocol was followed for $A$. advena except that third instar $F$. virgata was used instead of $P$. solenopsis.

When Aenasius arizonensis was introduced inside the setup containing Phenacoccus solenopsis and Oecophylla smaragdina, the population of $O$. smaragdina was 33.60 at 0 min of release, 75.60 at $10^{\text {th }} \mathrm{min}, 77.60$ at $20^{\text {th }}$ min and finally it was 50.20 at the end of $1 \mathrm{~h}$ study period. The number of surviving $A$. arizonensis was 15.00 at $0 \mathrm{~min}, 8.20$ at $10^{\text {th }} \mathrm{min}$, 3.40 at $20^{\text {th }}$ min and finally one at the end of the study period (Fig. 1). Both A. arizonensis and A. advena were prevented by the presence of $O$. smaragdina in accessing $P$. solenopsis and $F$. virgata. Oecophylla smaragdina was more aggressive towards both the species which is evident from reduction of their population at the end of $1 \mathrm{~h}$ study period. This coincides with the statement of Buckley and Gullan (1991) who stated that low parasitism rates of coccids was observed in the presence of the more aggressive Oecophylla and Solenopsis species.

When A. advena was released inside the cage with $F$. virgata and $O$. smaragdina, the population of $O$. smaragdina was 42.20 at 0 min of release, 54.00 at $10^{\text {th }} \mathrm{min}, 79.20$ at $20^{\text {th }}$ min and finally it was 72.00 at the end of $1 \mathrm{~h}$ study period. The number of surviving A. advena was 15.00 at 0 min, 5.40 at $10^{\text {th }} \mathrm{min}, 5.20$ at $20^{\text {th }} \mathrm{min}$ and finally 0.8 at the end of the study period (Fig. 2).

After 30 minutes $O$. smaragdina population increased in 
cages where $A$. advena was released (Fig. 2) but reverse was true in cages where $A$. arizonensis was released (Fig. 1). So, it can be assumed that $A$. arizonensis tackled $O$. smaragdina better than $A$. advena which was also evident by high per cent parasitism. This is supported by Martinez-Ferrer et al. (2003) who reported that some parasitoids have developed escape strategies from ants to improve their efficiency, others are so ant sensitive that after an encounter with ants, they are deterred not only by ants, but by any moving object including other parasitoids or the host itself, thereby greatly reducing their potential as biological control agents.

Per cent parasitism was 74.40 and 62.40 in control for A. arizonensis and $A$. advena, respectively; it was 13.60 and 10.00 in treatment with $O$. smaragdina for $A$. arizonensis and $A$. advena, respectively (Fig. 3 ). The per cent mortality recorded due to $O$. smaragdina attack was 93.33 and 94.67 for $A$. arizonensis and $A$. advena, respectively at the end of $1 \mathrm{~h}$ study period (Fig. 4). Oecophylla smaragdina not only affected per cent parasitism of both parasitoid species (Fig. 3) but also caused direct mortality (Fig. 4) which reduced parasitoid population considerably. This was earlier confirmed by Daane et al., (2007) who noticed that complete absence of parasitoids in vineyards infected with Pseudococcus maritimus attended by Linepithema humile. This is further supported by several

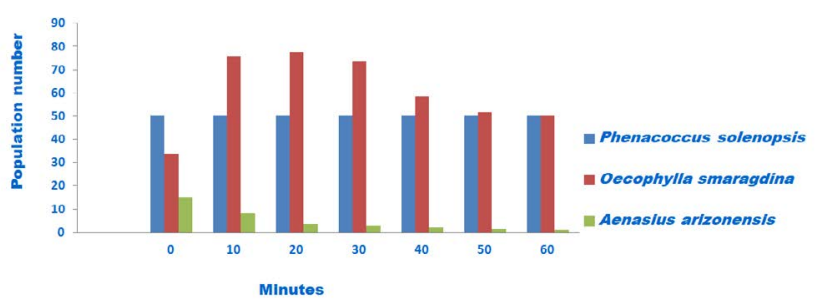

Fig. 1. Influence of Oecophylla smaragdina on number of Phenacoccus solenopsis and Aenasius arizonensis.

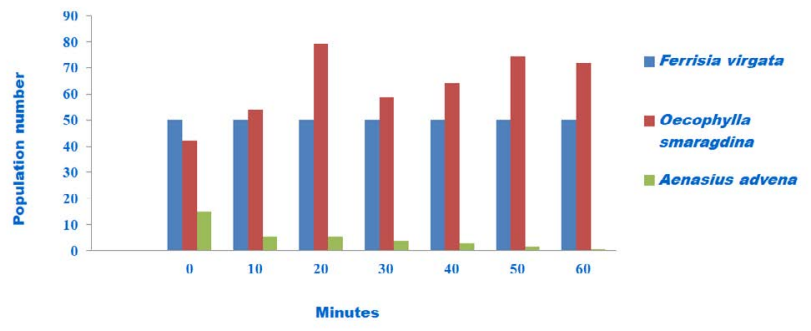

Fig. 2. Influence of Oecophylla smaragdina on number of Ferrisia virgata and Aenasius advena. other studies, which pointed out that the activities of natural enemies of mealybugs are often disrupted by some species of tending ants, compromising the parasitization potential of mealybugs' natural enemies and inducing further outbreaks of these economically important pests (Daane et al., 2007; Mgocheki et al., 2009; Tollerup et al., 2007). The mutualistic relationship between some ants and mealybug species is linked to the mealybugs' honeydew, which constitutes an important food resource for ants, implying that the latter are capable of employing strong territorial defences and aggressive tendencies that might end up disrupting or killing parasitoids and/or predators just to protect the mealybugs (Tanga, 2012; Mansour et al., 2012). Similarly, Tanga et al. (2016) also reported that Anagyrus pseudococci also suffered significantly high direct mortality due to encounters with Oecophylla longinoda workers, which led to a quick decline in parasitoid populations over time. Thus, field studies are needed to validate the present findings. Future field releases of parasitoids to control invasive mealybugs must be done with caution taking into account the biotic interference between natural enemies.

\section{ACKNOWLEDGEMENT}

Our special thanks to Dr. S. Suresh, Tamil Nadu Agricultural University, Coimbatore for the identification of the mealybugs and to Ms. Sheela, Zoological Survey of India,

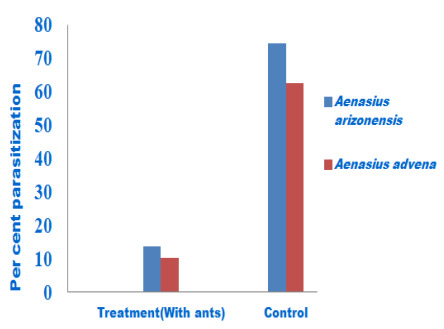

Fig. 3. Influence of Oecophylla smaragdina on per cent parasitization by Aenasius arizonensis and $A$. advena.

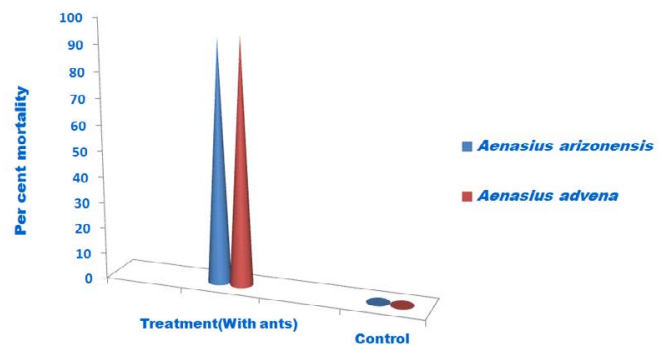

Fig. 4. Influence of Oecophylla smaragdina on per cent mortality of Aenasius arizonensis and A. advena. 
Kolkatta for the identification of ants.

\section{REFERENCES}

Buckley RC.1987. Interactions involving plants, Homoptera, and ants. Ann Ecol Syst. 18: 111-135. https://doi.org/10.1146/annurev.es.18.110187.000551

Buckley R, Gullan P. 1991. More aggressive ant species (Hymenoptera: Formicidae) provide better protection for soft scales and mealybugs (Homoptera: Coccidae, Pseudococcidae). Biotropica 23: 282-286. https://doi. org $/ 10.2307 / 2388205$

Carroll CR, Janzen DH. 1973. Ecology of foraging by ants. Annu Rev Ecol Evol Syst. 4: 231-257. https://doi. org/10.1146/annurev.es.04.110173.001311

Daane KM, Sime KR, Fallon J, Cooper ML. 2007. Impacts of Argentine ants on mealybugs and their natural enemies in California's coastal vineyards. Ecol Entomol. 32: 583596. https://doi.org/10.1111/j.1365-2311.2007.00910.x

Dhawan AK, Saini S, Singh K, Bharathi M. 2008. Toxicity of some new insecticides against Phenacoccus solenopsis (Tinsley) [Hemiptera: Pseudococcidae] on cotton. J Insect Sci. 21: 103-105.

Hölldobler B, Wilson EO. 1990. The Ants. The Belknap Press of Harvard University Press: Cambridge, MA, USA. p. 732. https://doi.org/10.1007/978-3-662-10306-7

Jiggins C, Majerus MEN, Gough U. 1993. Ant defence of colonies of Aphis fabae. Br J Entomol Nat Hist. 6: 129-137.

Mansour R, Gaetana M, Alessandra LP, Kaouthar GL, Agatino RA. 2012. Survey of scale insects (Hemiptera: Coccoidea) and tending ants in Tunisian vineyards. J Plant Prot Res. 51: 197-203.

Martinez-Ferrer MT, Grafton-Cardwell EE, Shorey HH. 2003. Disruption of parasitism of the California red scale (Homoptera: Diaspididae) by three ant species (Hymenoptera: Formicidae). Biol Control 26: 279-286. https://doi.org/10.1016/S1049-9644(02)00158-5
Mgocheki N, Addison P. 2009. Interference of ants (Hymenoptera: Formicidae) with biological control of the vine mealybug Planococcus ficus (Signoret) (Hemiptera: Pseudococcidae). Biol Control 49: 108-185. https://doi.org/10.1016/j.biocontrol.2009.02.001

Nalini T, Manickavasagam S. 2011. Records of Encyrtidae (Hymenoptera: Chalcidoidea) parasitoids on mealybugs (Hemiptera: Pseudococcidae) from Tamil Nadu, India. Check List 7: 510-515. https://doi.org/10.15560/7.4.510

Noyes JS. 2000. Encyrtidae of Costa Rica (Hymenoptera: Chalcidoidea), 1. The subfamily Tetracneminae, parasitoids of mealybugs (Homoptera: Pseudococcidae). Mem Am Entomol Inst. 62: pp. 355.

Suresh S, Jothimani R, Sivasubrmanian P, Karuppuchamy P, Samiyappan R, Jonathan EI. 2010. Invasive mealybugs of Tamil Nadu and their management. Karnataka J Agric Sci. 23: 6-9.

Suresh S, Kavitha PC. 2007. New records of coccoids in India. Proc. XI International Symposium on Scale Insect Studies, Oeiras, Portugal, pp. 24-27. PMid:17408223

Tanga MC. 2012. Bio-Ecology of the Mango Mealybug, Rastrococcusiceryoides Green (Hemiptera: Pseudococcidae) and its Associated Natural Enemies in Kenya and Tanzania. $\mathrm{Ph}$.D. Thesis, University of Pretoria, Pretoria, South Africa.

Tanga CM, Ekesi S, Govender P, Nderitu PW, Mohamed SA. 2016. Antagonistic Interactions between the African Weaver Ant Oecophylla longinoda and the Parasitoid Anagyrus pseudococci Potentially Limits Suppression of the Invasive Mealybug Rastrococcus iceryoides. Insects 7: 1-17. https://doi.org/10.3390/insects7010001 PMid:26703741 PMCid:PMC4808781

Tollerup K, Rust MK, Klotz JH. 2007. Formica perpilosa, an emerging pest in vineyards. J Agric Urban Entomol. 24: 147-158. https://doi.org/10.3954/1523-5475-24.3.147

Wimp GM, Whitham TG. 2001. Biodiversity consequences of predation and host plant hybridization on an aphid-ant mutualism. Ecology 82: 440-452. https://doi. org/10.2307/2679871 